\title{
Validation of the Eighth American Joint Committee on Cancer Staging System for Distal Bile Duct Carcinoma
}

\author{
Sun-Young Jun, $\mathrm{MD}, \mathrm{PhD}{ }^{1}$ \\ You-Na Sung, MD2 \\ Jae Hoon Lee, MD, PhD \\ Kwang-Min Park, MD, PhD \\ Young-Joo Lee, MD, PhD 3 \\ Seung-Mo Hong, MD, PhD²
}

${ }^{1}$ Department of Pathology, Incheon St. Mary's Hospital, College of Medicine, The Catholic University of Korea, Incheon, Departments of ${ }^{2}$ Pathology and ${ }^{3}$ Surgery, Asan Medical Center, University of Ulsan College of Medicine, Seoul, Korea

\begin{abstract}
Purpose
T category of the eighth edition of the American Joint Committee on Cancer (AJCC) staging system for distal bile duct carcinoma (DBDC) was changed to include tumor invasion depth measurement, while the $\mathrm{N}$ category adopted a 3-tier classification system based on the number of metastatic nodes.
\end{abstract}

\section{Materials and Methods}

To validate cancer staging, a total of 200 surgically resected DBDCs were staged and compared according to the seventh and eighth editions.

\section{Results}

T categories included T1 ( $n=37,18.5 \%)$, T2 ( $n=114,57.0 \%)$, and T3 ( $n=49,24.5 \%)$. N categories included N0 ( $n=133,66.5 \%), N 1(n=50,25.0 \%)$, and N2 ( $n=17,8.5 \%)$. Stage groupings included I ( $n=33,16.5 \%)$, II $(n=150,75.0 \%)$, and III ( $n=17,8.5 \%)$. The overall 5-year survival rates (5-YSRs) of T1, T2, and T3 were 59.3\%, 42.4\%, and 12.2\%, respectively. $\mathrm{T}$ category could discriminate patient survival by both pairwise ( $\mathrm{T} 1$ and $\mathrm{T} 2, \mathrm{p}=0.011$; $\mathrm{T} 2$ and $\mathrm{T} 3, \mathrm{p}<0.001)$ and overall $(\mathrm{p}<0.001$ ) comparisons. The overall 5-YSRs of N0, N1, and N2 were $47.3 \%, 17.0 \%$, and $14.7 \%$, respectively. $\mathrm{N}$ category could partly discriminate patient survival by both pairwise (N0 and N1, $\mathrm{p}<0.001$; N1 and N2, $\mathrm{p}=0.579$ ) and overall ( $\mathrm{p}$ 0.001 ) comparisons. The overall 5-YSRs of stages I, II, and III were 59.0\%, 35.4\%, and $14.7 \%$, respectively. Stages could distinguish patient survival by both pairwise (I and II, $p=0.002 ;$ II and III, $p=0.015)$ and overall $(p<0.001)$ comparisons. On multivariate analyses, $T$ and $N$ categories $(p=0.014$ and $p=0.029)$ and pancreatic invasion $(p=0.006)$ remained significant prognostic factors.

\section{Conclusion}

The T and $\mathrm{N}$ categories of the eighth edition AJCC staging system for DBDC accurately predict patient prognosis.
Department of Pathology, Asan Medical Center, University of Ulsan College of Medicine,

88 Olympic-ro 43-gil, Songpa-gu,

Seoul 05505, Korea

Tel: 82-2-3010-4558

Fax: 82-2-472-7898

E-mail: smhong28@gmail.com

Received December 16, 2017

Accepted March 1, 2018

Published Online March 2, 2018
Key words

Bile duct, Extrahepatic, Cholangiocarcinoma, Neoplasm, Staging

\section{Introduction}

Bile duct carcinomas, or cholangiocarcinomas, account for $3 \%$ of all gastrointestinal cancers worldwide [1], and their incidence is higher in Eastern Asian countries, including Korea, China, and Thailand [2]. Bile duct carcinomas can be further classified as intrahepatic, perihilar, and distal bile duct carcinomas (DBDCs) [3], and DBDCs compromise about $30 \%$ of all bile duct carcinomas [3]. In the United States, it is estimated that about 10,910 Americans will be diagnosed with carcinomas of the gallbladder and extrahepatic bile duct in 2015 [4].

Although the American Joint Committee on Cancer (AJCC) has changed the staging system of extrahepatic bile duct (EBD) carcinoma seven times in the last decades [5,6], those staging systems have been criticized for being inaccurate in estimating prognosis [7-9]. First, the previous staging sys- 
Table 1. AJCC staging system for distal bile duct carcinoma

\begin{tabular}{|c|c|c|c|}
\hline \multicolumn{2}{|r|}{ AJCC seventh edition } & \multicolumn{2}{|r|}{ AJCC eighth edition } \\
\hline \multicolumn{4}{|c|}{ Primary tumor $(\mathrm{T})$} \\
\hline $\mathrm{T} 1$ & Tumor confined to the bile duct histologically & $\mathrm{T} 1$ & Depth of invasion $<5 \mathrm{~mm}$ \\
\hline $\mathrm{T} 2$ & Tumor invades beyond the wall of bile duct & $\mathrm{T} 2$ & Depth of invasion 5-12 mm \\
\hline T3 & $\begin{array}{l}\text { Tumor invades gallbladder, pancreas, duodenum, } \\
\text { or other adjacent organs without involvement } \\
\text { of celiac axis or the superior mesenteric artery }\end{array}$ & T3 & Depth of invasion $>12 \mathrm{~mm}$ \\
\hline $\mathrm{T} 4$ & $\begin{array}{l}\text { Tumor involves the celiac axis or the superior } \\
\text { mesenteric artery }\end{array}$ & $\mathrm{T} 4$ & $\begin{array}{l}\text { Tumor involves the celiac axis or the superior } \\
\text { mesenteric artery }\end{array}$ \\
\hline \multicolumn{4}{|c|}{ Regional lymph nodes $(\mathrm{N})$} \\
\hline N0 & No regional lymph node metastasis & No & No regional lymph node metastasis \\
\hline \multirow[t]{2}{*}{ N1 } & Regional lymph node metastasis & N1 & Metastasis in 1-3 regional lymph nodes \\
\hline & & N2 & Metastasis in $\geq 4$ regional lymph nodes \\
\hline \multicolumn{4}{|c|}{ Distant metastasis (M) } \\
\hline M0 & No distant metastasis & M0 & No distant metastasis \\
\hline M1 & Distant metastasis & M1 & Distant metastasis \\
\hline \multicolumn{4}{|c|}{ Stage grouping } \\
\hline IA & T1N0M0 & I & T1N0M0 \\
\hline IB & T2N0M0 & IIA & T1N1M0 or T2N0M0 \\
\hline IIA & T3N0M0 & IIB & T2N1M0 or T3, N0-1, M0 \\
\hline IIB & T1-3, N1M0 & IIIA & $\mathrm{T} 1-3, \mathrm{~N} 2 \mathrm{M} 0$ \\
\hline III & T4, any N, M0 & IIIB & T4, any N, M0 \\
\hline IV & Any T, any N, M1 & IV & Any T, any N, M1 \\
\hline
\end{tabular}

AJCC, American Joint Committee on Cancer.

tems did not take into consideration the histologic characteristics of smooth muscle distribution in the EBD. Cancer staging of DBDCs was separated from the staging of proximal or perihilar bile duct carcinoma from the seventh edition of the AJCC staging manual [10]. However, the terminology used in the sixth and seventh editions of the AJCC staging system, which defined T1 and T2 diseases as "confined to the bile duct histologically" and "beyond the wall of the bile duct," was unclear and problematic $[10,11]$, especially when marked stromal response of the invasive carcinoma presents and obscures the lower boundary of the bile duct wall [8]. To overcome the problems of the previous editions of the AJCC cancer staging system for DBDC, an alternative method of T classification was proposed, which measured the depth of tumor invasion from the basal lamina of the adjacent normal epithelium to the most deeply infiltrating tumor cells, and categorized invasion depth as T1, <5 mm; T2, 5-12 mm; and T3, > $12 \mathrm{~mm}$ [12]. This method more powerfully predicted survival in patients with DBDCs than the previously used $\mathrm{T}$ classification of seventh edition $[9,12,13]$, and was ultimately incorporated in the T category of the eighth edition [14].

Conversely, the $\mathrm{N}$ category of seventh edition AJCC staging system was simple to evaluate the presence or absence of metastatic nodes. Several later studies demonstrated the characteristics of nodal metastasis, including location of the involved lymph nodes, lymphatic spread, and micrometastasis [15-20]. Previous studies by Moon et al. [13] and Schwarz et al. [21] demonstrated that a minimum of 10 lymph nodes were required to assess the accurate $\mathrm{N}$ category of DBDC. In addition, several studies emphasized the significance of the 3 tiers of $\mathrm{N}$ classification as a prognostic indicator $[13,22,23]$.

In the eighth edition of the AJCC cancer staging for DBDC, the $\mathrm{T}$ category was changed according to invasion depth as follows: T1, < $5 \mathrm{~mm}$; T2, 5-12 mm; and T3, > $12 \mathrm{~mm}$. The N category was classified into 3 -tiers based on the number of metastatic nodes: N0, no nodal metastasis; N1, 1 to 3 nodal metastases; and N2, 4 or more nodal metastases. A summary of the changes between the seventh and eighth editions of AJCC staging for DBDCs is described in Table 1. Recently, Gonzalez et al. [1] reported a size-based T category for staging DBDCs and revealed its significant relationship with patient survival differences, specifically for intra-pancreatic type DBDCs. They stratified 47 intra-pancreatic DBDC cases based on tumor size as follows: $<2 \mathrm{~cm}, 2-4 \mathrm{~cm}$, and $>4 \mathrm{~cm}$ [1].

To validate the new eighth edition of the AJCC cancer staging system for DBDCs, we compared the clinicopathologic factors including patient survival based on the seventh and 
eighth editions of the AJCC cancer staging system for DBDC. In addition, we evaluated the prognostic relevance of sizebased criteria for the staging for DBDC.

\section{Materials and Methods}

\section{Case selection}

All cases of surgically resected primary DBDCs between May 2010 and June 2012 from Asan Medical Center were collected. Carcinomas originating in the mucosa of the bile duct and from the junction of the cystic duct-common bile duct to the ampulla of Vater were included in this study. Carcinomas arising in the ampulla of Vater or pancreas were excluded. Finally, 200 cases of DBDCs were included in this study.

Clinical data included patient sex and age, operation date, most recent follow-up date, operation method, postoperative radiation therapy and chemotherapy, and survival status. Pathological data included tumor size and location, growth pattern (papillary, nodular, or diffusely infiltrative pattern), histologic subtype, tumor grade, margin status, perineural and lymphovascular invasion, pancreatic, duodenal, and gallbladder invasion, nodal metastasis, and stage grouping evaluation based on the seventh and eighth editions of the AJCC cancer staging system $[10,14]$. Tumor size was grossly evaluated and microscopically confirmed. When the discrepancy was present between two measurements, tumor size by microscopic measurement was selected, which was previously described elsewhere [1]. The tumor size was further categorized based on greatest dimension as follows: $<2 \mathrm{~cm}$, 2-4 cm, and $>4 \mathrm{~cm}[1]$.

The depth of cancer invasion was measured on slides containing the primary DBDC and was defined as the area of deepest infiltration from the mucosal surface, e.g., from the basal lamina of the adjacent normal epithelium to the most deeply advanced tumor cells. For cases containing high grade dysplasia (or biliary intraepithelial neoplasia [BilIN]3) at the periphery of the invasive tumors, the basal lamina of the high grade dysplasia (or BilIN-3) was used as the reference, which was previously described [12]. The maximum depth of tumor invasion was categorized into 3 groups: T1, < $5 \mathrm{~mm}$; T2, 5-12 mm; and T3, > $12 \mathrm{~mm}[7,12]$.

DBDCs were further classified based on location in the distal bile duct (DBD) as follows: When the tumor was located within the intrapancreatic DBD, the tumor was classified as "intra-pancreatic type"; when the tumor was located in the DBD outside of the pancreas between the junction of cystic duct-common bile duct to just before entering intra-pancre-

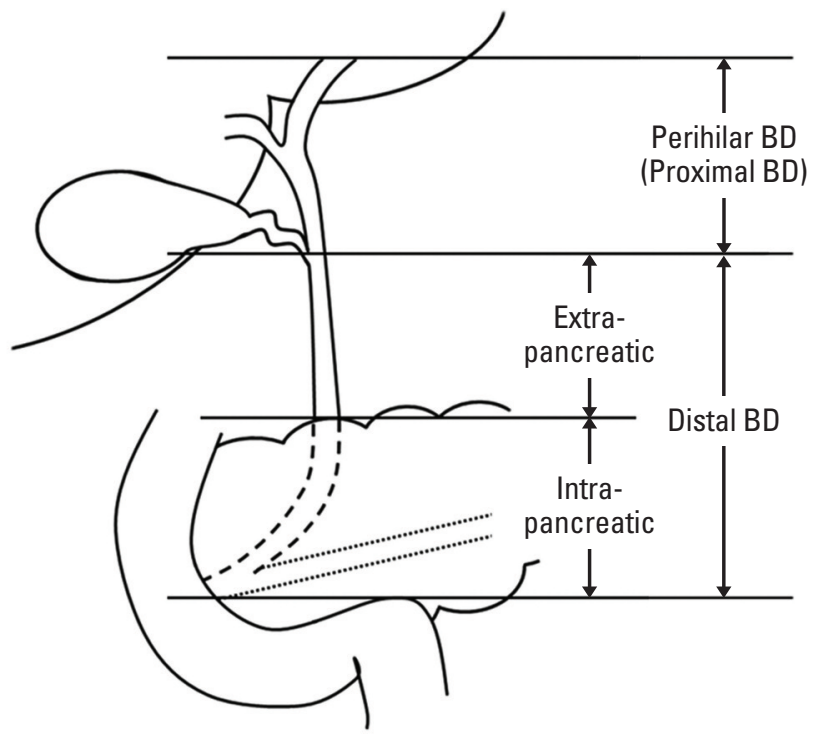

Fig. 1. Schematic drawing of the distal bile duct (BD).

atic DBD, the tumor was classified as "extra-pancreatic type"; when the tumor diffusely involved intra- and extra-pancreatic DBDs, the tumor was classified as "both intra- and extrapancreatic type" (Fig. 1). Tumor grading was classified as low (well to moderately differentiated tumors) and high grade (poorly differentiated and undifferentiated tumors) [24].

\section{Statistical analysis}

Statistical analyses were performed with SPSS software ver. 17.0 (SPSS Inc., Chicago, IL). Categorical data were analyzed using Student's t test, the chi-square test, or Fisher's exact test. The survival rate was estimated using the KaplanMeier method and the log-rank test was used to calculate its associations with various clinicopathologic factors. The significance of any prognostic factors was investigated with the Cox proportional hazards model. $\mathrm{p}$-values of $<0.05$ were considered to denote statistical significance.

\section{Ethical statement}

The Institutional Review Board of Asan Medical Center approved this study (2013-0527) with a waiver of the informed consent. 
Table 2. Characteristics of patients with distal bile duct carcinoma

\section{Variable}

No. $(\%)(\mathrm{n}=200)$

\section{Operation}

Pancreatoduodenectomy including Whipple $170(85.0)$

Bile duct resection

$30(15.0)$

$65.4 \pm 9.2$

$55(27.5)$

$145(72.5)$

$\geq 60$

$137(68.5)$

Male

$63(31.5)$

Female

$168(84.0)$

Intra-pancreatic

$30(15.0)$

Extra-pancreatic

$2(1.0)$

Growth pattern

Papillary

$12(6.0)$

Nodular

$33(16.5)$

Diffusely infiltrative

$155(77.5)$

Histologic subtype

Tubular adenocarcinoma $\quad 198(99.0)$

Mucinous carcinoma $\quad 1(0.5)$

Undifferentiated carcinoma $\quad 1(0.5)$

Grade

Low $167(83.5)$

High 33 (16.5)

Size, mean \pm SD $(\mathrm{cm}) \quad 2.9 \pm 1.2$

$<2 \quad 39(19.5)$

$2-4 \quad 132(66.0)$

$>4 \quad 29(14.5)$

Pancreatic invasion ${ }^{\text {a) }}$

No $53(31.2)$

Yes $117(68.8)$

Duodenal invasiona)

$\begin{array}{lr}\text { No } & 116 \text { (68.2) } \\ \text { Yes } & 54(31.8)\end{array}$

Cystic duct of gallbladder invasion

No $163(81.5)$

Yes $\quad 37$ (18.5)

Resection margin status of the bile duct

No involvement

$160(80.0)$

Involved by cancer

$40(20.0)$

Lymphovascular invasion

$81(40.5)$

Perineural invasion

$166(83.0)$

$\mathrm{T}$ category, seventh edition

\begin{tabular}{cc} 
T1 & $12(6.0)$ \\
T2 & $40(20.0)$ \\
T3 & $148(74.0)$ \\
T4 & 0 \\
\hline
\end{tabular}

(Continued)
Table 2. Continued

\section{Variable}

No. $(\%)(\mathrm{n}=200)$

$\mathrm{N}$ category, seventh edition

N0 $133(66.5)$

N1

$67(33.5)$

AJCC stage grouping, seventh edition

IA $12(6.0)$

IB $33(16.5)$

IIA $\quad 88(44.0)$

IIB $\quad 67(33.5)$

III 0

IV 0

Depth of invasion, mean \pm SD (mm) $\quad 9.3 \pm 5.0$

Total nodes assessed, mean \pm SD $\quad 12.1 \pm 7.5$

No. of positive nodes, mean \pm SD $\quad 0.9 \pm 1.9$

$\mathrm{T}$ category, eighth edition

T1 $37(18.5)$

T2 $114(57.0)$

T3 $49(24.5)$

T4 0

$\mathrm{N}$ category, eighth edition

No $133(66.5)$

N1 $50(25.0)$

$\mathrm{N} 2 \quad 17(8.5)$

AJCC stage grouping, eighth edition

I $33(16.5)$

IIA $\quad 85(42.5)$

IIB $\quad 65(32.5)$

IIIA $\quad 17$ (8.5)

IIIB 0

IV 0

SD, standard deviation; AJCC, American Joint Committee on Cancer. ${ }^{a}$ Calculated using only patients with sufficient available data.

\section{Results}

\section{Patient characteristics}

Patient clinicopathologic characteristics are summarized in Table 2. The male to female ratio of the patients was 2.2 with a median age at resection of 67.0 years (range, 35 to 82 years). There were 168 intra-pancreatic (84.0\%), 30 extra-pancreatic $(15.0 \%)$, and 2 both intra- and extra-pancreatic (1.0\%) DBDCs. The mean tumor size was $2.9 \pm 1.2 \mathrm{~cm}$. About twothirds of the cases were between 2 and $4 \mathrm{~cm}(132 / 200,66.0 \%)$. One hundred seventy cases $(85.0 \%)$ were pancreatoduodenectomy specimens including Whipple operation or pylorus-preserving pancreaticoduodenectomy, and the 
Table 3. Association between T and N categories of the eighth AJCC and clinicopathologic factors in distal bile duct carcinoma patients

\begin{tabular}{|c|c|c|c|c|c|c|}
\hline \multirow{2}{*}{ Clinicopathologic factor } & \multicolumn{3}{|c|}{$\mathrm{T}$ category } & \multicolumn{3}{|c|}{$\mathrm{N}$ category } \\
\hline & T1 & T2 & T3 & No & N1 & N2 \\
\hline No. of patients & $37(18)$ & $114(57)$ & $49(25)$ & $133(67)$ & $50(25)$ & $17(8)$ \\
\hline Age, mean $\pm S D(y r)$ & $65.5 \pm 8.2$ & $66.0 \pm 9.1$ & $64.0 \pm 10.1$ & $65.3 \pm 9.4$ & $65.9 \pm 9.2$ & $64.3 \pm 7.8$ \\
\hline p-value & & 0.453 & & & 0.815 & \\
\hline \multicolumn{7}{|l|}{ Age (yr) } \\
\hline$<60$ & $9(24)$ & $27(24)$ & $19(39)$ & $36(27)$ & $15(30)$ & $4(23)$ \\
\hline$\geq 60$ & $28(76)$ & $87(76)$ & $30(61)$ & $97(73)$ & $35(70)$ & $13(77)$ \\
\hline p-value & & 0.126 & & & 0.859 & \\
\hline \multicolumn{7}{|l|}{ Sex } \\
\hline Male & $25(68)$ & $76(67)$ & $36(74)$ & $92(69)$ & $34(68)$ & $11(65)$ \\
\hline Female & $12(32)$ & $38(33)$ & $13(26)$ & $41(31)$ & $16(32)$ & $6(35)$ \\
\hline $\mathrm{p}$-value & & 0.686 & & & 0.929 & \\
\hline \multicolumn{7}{|l|}{ Location } \\
\hline Intra-pancreatic & $7(19)$ & $20(17)$ & $3(6)$ & $18(13)$ & $11(22)$ & $1(6)$ \\
\hline Extra-pancreatic & $30(81)$ & $93(82)$ & $45(92)$ & $115(87)$ & $38(76)$ & $15(88)$ \\
\hline Both intra- and extra-pancreatic & 0 & $1(1)$ & $1(2)$ & 0 & $1(2)$ & $1(6)$ \\
\hline p-value & & 0.202 & & & 0.052 & \\
\hline \multicolumn{7}{|l|}{ Growth pattern } \\
\hline Papillary & $10(27)$ & $1(1)$ & $1(2)$ & $10(7)$ & 0 & $2(12)$ \\
\hline Nodular & $7(19)$ & $21(18)$ & $5(10)$ & $21(16)$ & $8(16)$ & $4(23)$ \\
\hline Diffusely infiltrative & $20(54)$ & $92(81)$ & $43(88)$ & $102(77)$ & $42(84)$ & $11(65)$ \\
\hline $\mathrm{p}$-value & & $<0.001^{\text {a) }}$ & & & 0.130 & \\
\hline \multicolumn{7}{|l|}{ Size $(\mathrm{cm})$} \\
\hline$<2$ & $11(30)$ & $26(23)$ & $2(4)$ & $32(24)$ & $6(12)$ & $1(6)$ \\
\hline $2-4$ & $22(59)$ & $70(61)$ & $40(82)$ & $83(62)$ & $37(74)$ & $12(71)$ \\
\hline$\geq 4$ & $4(11)$ & $18(16)$ & $7(14)$ & $18(14)$ & $7(14)$ & $4(23)$ \\
\hline p-value & & $0.022^{\mathrm{a})}$ & & & 0.172 & \\
\hline \multicolumn{7}{|l|}{ Histological subtype } \\
\hline Tubular adenocarcinoma & $37(100)$ & $114(100)$ & $47(96)$ & $132(99)$ & $50(100)$ & $16(94)$ \\
\hline Mucinous carcinoma & 0 & 0 & $1(2)$ & 0 & 0 & $1(6)$ \\
\hline Undifferentiated carcinoma & 0 & 0 & $1(2)$ & $1(1)$ & 0 & 0 \\
\hline p-value & & 0.184 & & & 0.163 & \\
\hline \multicolumn{7}{|l|}{ Grade } \\
\hline Low & $33(89)$ & $96(84)$ & $38(78)$ & $113(85)$ & $42(84)$ & $12(71)$ \\
\hline High & $4(11)$ & $18(16)$ & $11(22)$ & $20(15)$ & $8(16)$ & $5(29)$ \\
\hline $\mathrm{p}$-value & & 0.338 & & & 0.321 & \\
\hline \multicolumn{7}{|c|}{ Resection margin status of the bile duct } \\
\hline No involvement & $33(89)$ & $91(80)$ & $36(74)$ & $111(84)$ & $35(70)$ & $14(82)$ \\
\hline Involved by cancer & $4(11)$ & $23(20)$ & $13(26)$ & $22(16)$ & $15(30)$ & $3(18)$ \\
\hline $\mathrm{p}$-value & & 0.196 & & & 0.124 & \\
\hline \multicolumn{7}{|l|}{ Lymphovascular invasion } \\
\hline No & $29(78)$ & $71(62)$ & $19(39)$ & $90(68)$ & $24(48)$ & $5(29)$ \\
\hline Yes & $8(22)$ & $43(38)$ & $30(61)$ & $43(32)$ & $26(52)$ & $12(71)$ \\
\hline p-value & & $0.001^{\mathrm{a})}$ & & & $0.002^{\mathrm{a})}$ & \\
\hline \multicolumn{7}{|l|}{ Perineural invasion } \\
\hline No & $15(40)$ & $13(11)$ & $6(12)$ & $28(21)$ & $5(10)$ & $1(6)$ \\
\hline Yes & $22(60)$ & $101(89)$ & $43(88)$ & $105(79)$ & $45(90)$ & $16(94)$ \\
\hline p-value & & $<0.001^{\text {a) }}$ & & & 0.092 & \\
\hline
\end{tabular}

(Continued to the next page) 
Table 3. Continued

\begin{tabular}{|c|c|c|c|c|c|c|}
\hline \multirow{2}{*}{ Clinicopathologic factor } & \multicolumn{3}{|c|}{ T category } & \multicolumn{3}{|c|}{$\mathbf{N}$ category } \\
\hline & $\mathbf{T 1}$ & $\mathrm{T} 2$ & T3 & No & N1 & $\mathbf{N} 2$ \\
\hline \multicolumn{7}{|l|}{ Pancreatic invasion $^{\text {b) }}$} \\
\hline No & $20(67)$ & $27(29)$ & $6(13)$ & $43(37)$ & $8(20)$ & $2(12)$ \\
\hline Yes & $10(33)$ & $67(71)$ & $40(87)$ & $72(63)$ & $31(80)$ & $14(88)$ \\
\hline p-value & & $<0.001^{\mathrm{a})}$ & & & $0.034^{\mathrm{a})}$ & \\
\hline \multicolumn{7}{|l|}{ Duodenal invasion $^{\text {b) }}$} \\
\hline No & $28(93)$ & $70(75)$ & $18(39)$ & $89(77)$ & $22(56)$ & $5(31)$ \\
\hline Yes & $2(7)$ & $24(25)$ & $28(61)$ & $26(23)$ & $17(44)$ & $11(69)$ \\
\hline p-value & & $<0.001^{\text {a) }}$ & & & $<0.001^{\text {a) }}$ & \\
\hline \multicolumn{7}{|l|}{$\mathrm{N}$ category, eighth edition } \\
\hline N0 & $33(89)$ & $81(71)$ & $19(39)$ & - & - & - \\
\hline N1 (1-3) & $4(11)$ & $26(23)$ & $20(41)$ & - & - & - \\
\hline $\mathrm{N} 2(\geq 4)$ & 0 & $7(6)$ & $10(20)$ & - & - & - \\
\hline $\mathrm{p}$-value & & $<0.001^{\text {a) }}$ & & & - & \\
\hline
\end{tabular}

Values are presented as number $(\%)$ or mean \pm standard deviation. AJCC, American Joint Committee on Cancer; SD, standard deviation. ${ }^{a}$ Statistically significant $(\mathrm{p}<0.05),{ }^{\mathrm{b}}$ Calculated using only patients with sufficient available data.

remaining $30(15.0 \%)$ were specimens of bile duct resection with cholecystectomy. Post-operative radiation therapy and chemotherapy were performed in $37(18.5 \%)$ and $69(34.5 \%)$ patients, respectively. In the pathologic examination of bile duct resection specimens, the status of pancreatic or duodenal involvement by the tumor could not be completely evaluated. Consequently, involvements of the pancreas, duodenum, and / or cystic duct of the gallbladder was observed in $68.8 \%$ (117/ 170 cases), 31.8\% (54/170), and 18.5\% (37/200), respectively, with either single or multiple organ involvement. Lymphovascular and perineural invasions were frequently observed in $40.5 \%(n=81)$ and $83.0 \%(n=166)$ of cases, respectively. Involvement of resection margin of the bile duct by cancer was in $20.0 \%(n=40)$ of cases. The median followup period after surgical resection was 33.8 months (range, 1 to 63 months).

\section{Comparison between $\mathrm{T}$ and $\mathrm{N}$ categories of the eighth AJCC and clinicopathologic factors}

The associations between $\mathrm{T}$ and $\mathrm{N}$ categories of the eighth AJCC cancer staging scheme and clinicopathologic factors of patients with DBDCs are shown in Table 3. The patients with higher $\mathrm{T}$ category tended to have diffusely infiltrative pattern $(p<0.001)$, larger tumor $(p=0.022)$, and presence of perineural $(\mathrm{p}<0.001)$, lymphovascular $(\mathrm{p}=0.001)$, pancreatic $(\mathrm{p}<0.001)$, and duodenal $(\mathrm{p}<0.001)$ invasions. In addition, strong association was observed between $\mathrm{T}$ and $\mathrm{N}$ categories $(\mathrm{p}<0.001)$.

Similarly, the patients with higher $\mathrm{N}$ category tended to have more frequent lymphovascular $(\mathrm{p}=0.002)$, pancreatic $(\mathrm{p}=0.034)$, and duodenal $(\mathrm{p}<0.001)$ invasions.

\section{Patient survival based on $\mathrm{T}$ category}

The median depth of invasion of DBDC was $8.0 \mathrm{~mm}$ (range, 1 to $28 \mathrm{~mm}$ ). According to the eighth AJCC staging system, 37 cases were categorized as T1 (18.5\%), 114 as T2 $(57.0 \%)$, and 49 as T3 $(24.5 \%)$ tumors. The median survival time in patients with T2 and T3 tumors was 36.3 months and 19.9 months, respectively, while the median survival time in those with $\mathrm{T} 1$ was not reached. The 1-year, 3-year, and 5-year survival rates (YSRs) of patients with T1 tumors were 97.2\%, $80.3 \%$, and $59.3 \%$, respectively; conversely, those of patients with $\mathrm{T} 2$ tumors were significantly decreased at $86.0 \%, 50.4 \%$, and $42.4 \%$, respectively. The 1-, 3-, and 5-YSRs of patients with T3 tumors were also significantly decreased at $65.3 \%$, $28.6 \%$, and $12.2 \%$, respectively. Patients with DBDCs showed an overall significant survival difference based on the $\mathrm{T}$ category of the eighth edition scheme ( $\mathrm{p}<0.001)$ (Fig. 2A). When pairwise comparisons were performed, all pairs of $\mathrm{T}$ category showed significant differences in patient survival from each other (T1 and T2, $\mathrm{p}=0.011$; T2 and T3, $\mathrm{p}<0.001$ ).

Conversely, based on the seventh AJCC staging system, 12 were categorized as $\mathrm{T} 1(6.0 \%), 40$ as T2 $(20.0 \%)$, and 148 as $\mathrm{T} 3(74.0 \%)$ tumors. The median survival times in patients with T2 and T3 tumors were 41.2 months and 27.5 months, respectively, while the median survival time in those with T1 was not reached. The 1-, 3-, and 5-YSRs were all 91.7\% in patients with T1 tumors, $92.5 \%, 69.7 \%$, and $40.8 \%$ in patients 

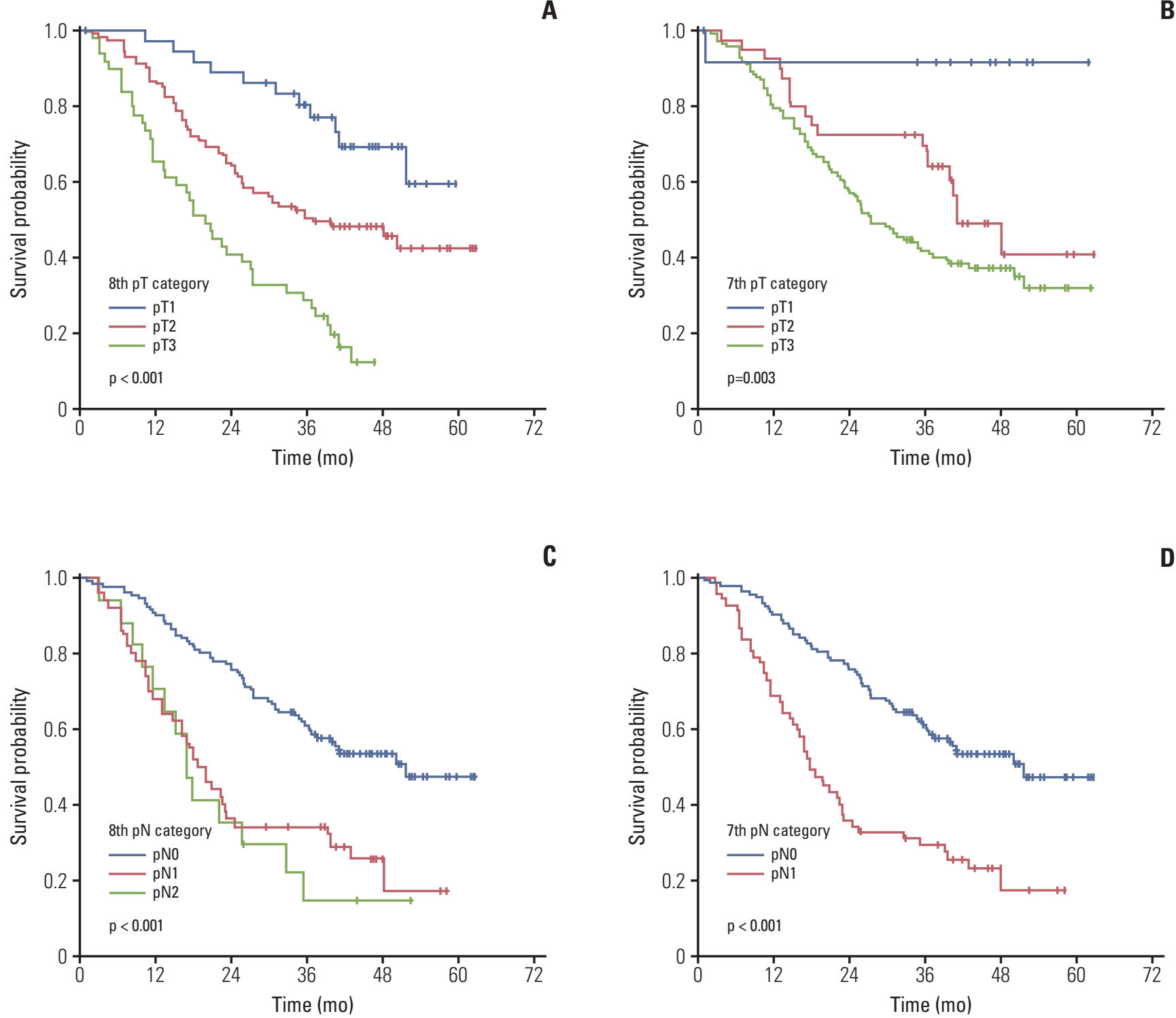

Fig. 2. Overall survival stratified by $\mathrm{T}$ and $\mathrm{N}$ categories of distal bile duct carcinomas according to the American Joint Committee on Cancer. T categories of the eighth edition (A) and the seventh edition (B) and $\mathrm{N}$ categories of the eighth edition (C) and the seventh edition (D).

with $\mathrm{T} 2$ tumors, and $79.6 \%, 41.7 \%$, and $32.0 \%$ in patients with T3 tumors, respectively. Patients with DBDCs showed an overall significant survival difference based on the T category of the seventh edition AJCC staging scheme $(\mathrm{p}=0.003)$ (Fig. 2B). The pairwise comparisons showed a significant difference between patients with $\mathrm{T} 1$ and $\mathrm{T} 2$ tumors $(\mathrm{p}=0.023)$; however, there was no significant survival difference between patients with $\mathrm{T} 2$ and $\mathrm{T} 3$ tumors $(\mathrm{p}=0.066)$.

\section{Patient survival based on $\mathrm{N}$ category}

The total number of examined nodes assessed ranged from 1 to 36 (mean, 12.1 \pm 7.5 ; median, 11.0). Among them, the number of metastatic nodes ranged from 0 to 11 (mean, $0.9 \pm 1.9$; median, 0 ). The majority of the tumors were N0 (133 cases, $66.5 \%$ ). According to the eighth AJCC staging system, nodal metastasis was seen in 67 cases, including $50 \mathrm{~N} 1$ $(25.0 \%)$ and $17 \mathrm{~N} 2(8.5 \%)$. Survival curves based on the N category are depicted in Fig. 2C and D. The 1-, 3-, and 5-YSRs 
A

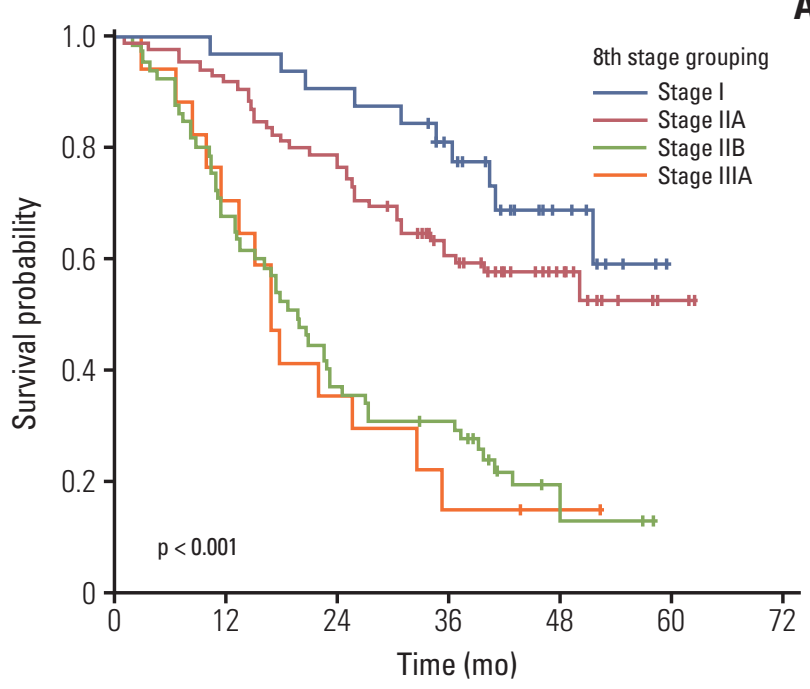

C

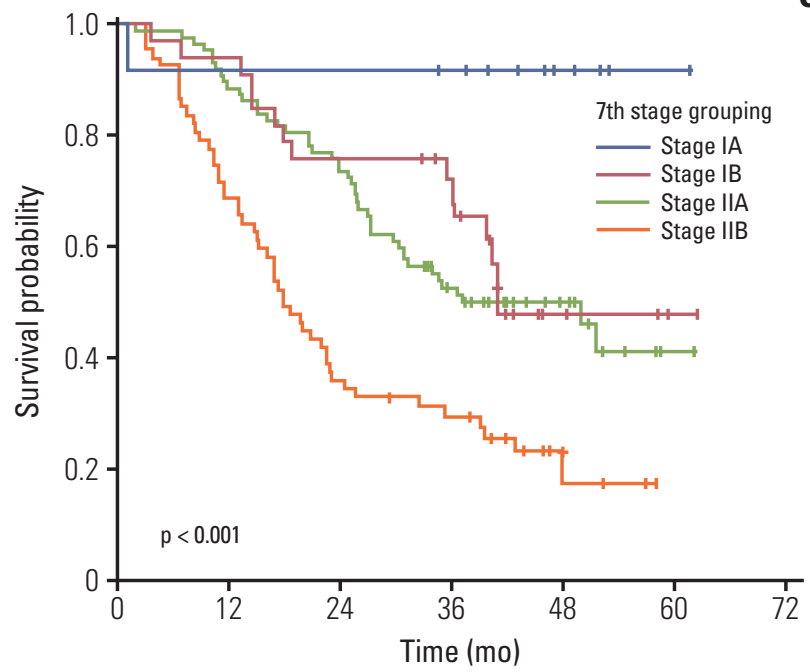

B

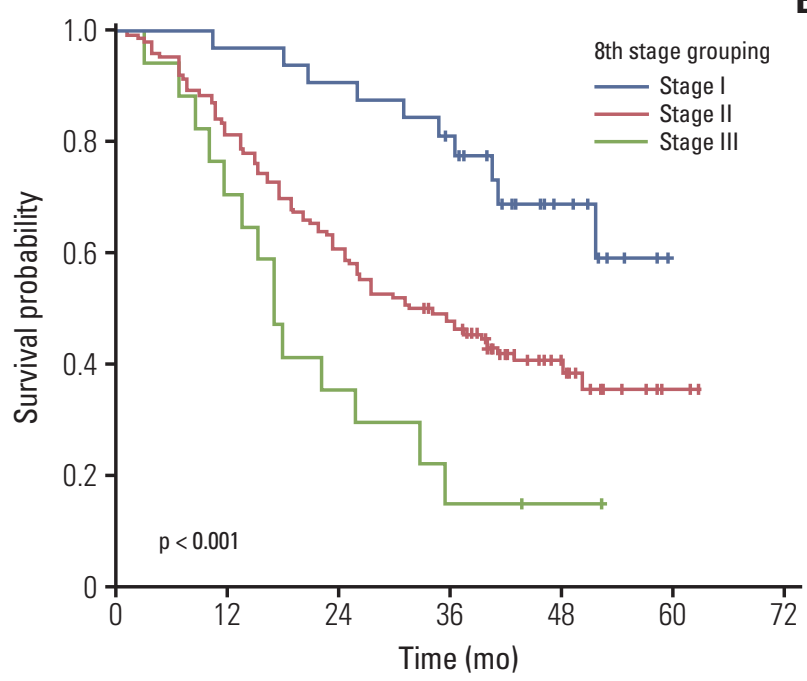

D

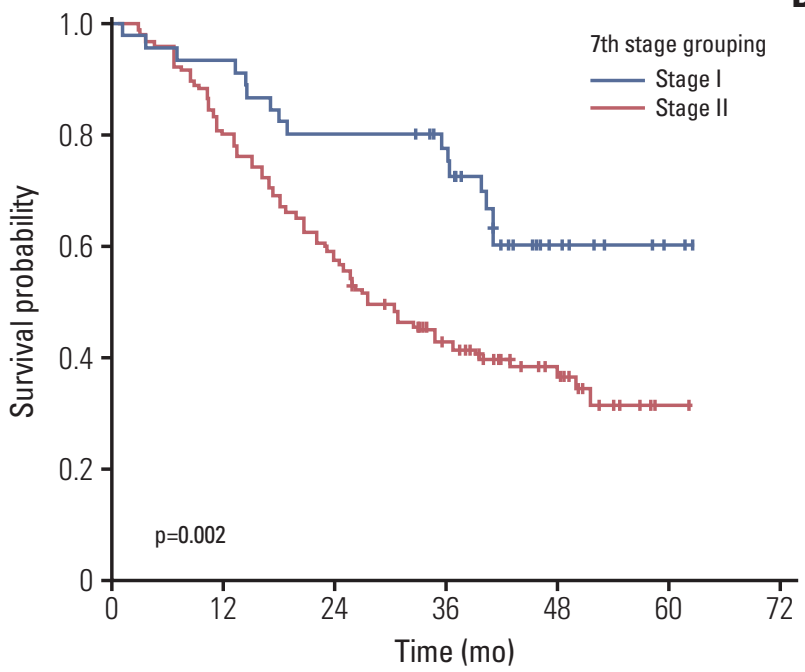

Fig. 3. Overall survival stratified by stage group of distal bile duct carcinomas according to the American Joint Committee on Cancer eighth edition (A and B) and seventh edition stage grouping (C and D).

in patients with N0 tumors were $90.2 \%, 61.1 \%$, and $47.3 \%$, respectively. Those in patients with $\mathrm{N} 1$ and $\mathrm{N} 2$ tumors were decreased, corresponding to $68.0 \%, 34.0 \%$, and $17.0 \%$ in N1 patients and $70.6 \%, 14.7 \%$, and $14.7 \%$ in N2 patients, respectively. Overall patient survival was significantly decreased among patients with metastatic nodes ( $\mathrm{p}<0.001)$ (Fig. 2C). The median survival times of patients with $\mathrm{N} 1$ and $\mathrm{N} 2$ tumors (18.8 and 17.0 months, respectively) were significantly shorter than that of patients with N0 (51.8 months; $\mathrm{p}<0.001$, each). However, the survival times of the patients with N1 and N2 tumors were not significantly different
( $\mathrm{p}=0.579$ ). The median survival time of the patients with metastatic nodes (18.0 months) was significantly shorter than that of those without metastatic nodes (51.8 months; $\mathrm{p}<$ 0.001 ). Therefore, patient survival was significantly decreased when the patients had metastatic nodes as defined by the seventh edition scheme (Fig. 2D).

\section{Patient survival based on AJCC stage grouping}

By the eighth edition definitions, the tumors were classified into stages I (33 cases, $16.5 \%)$, IIA $(85,42.5 \%)$, IIB (65, 
A
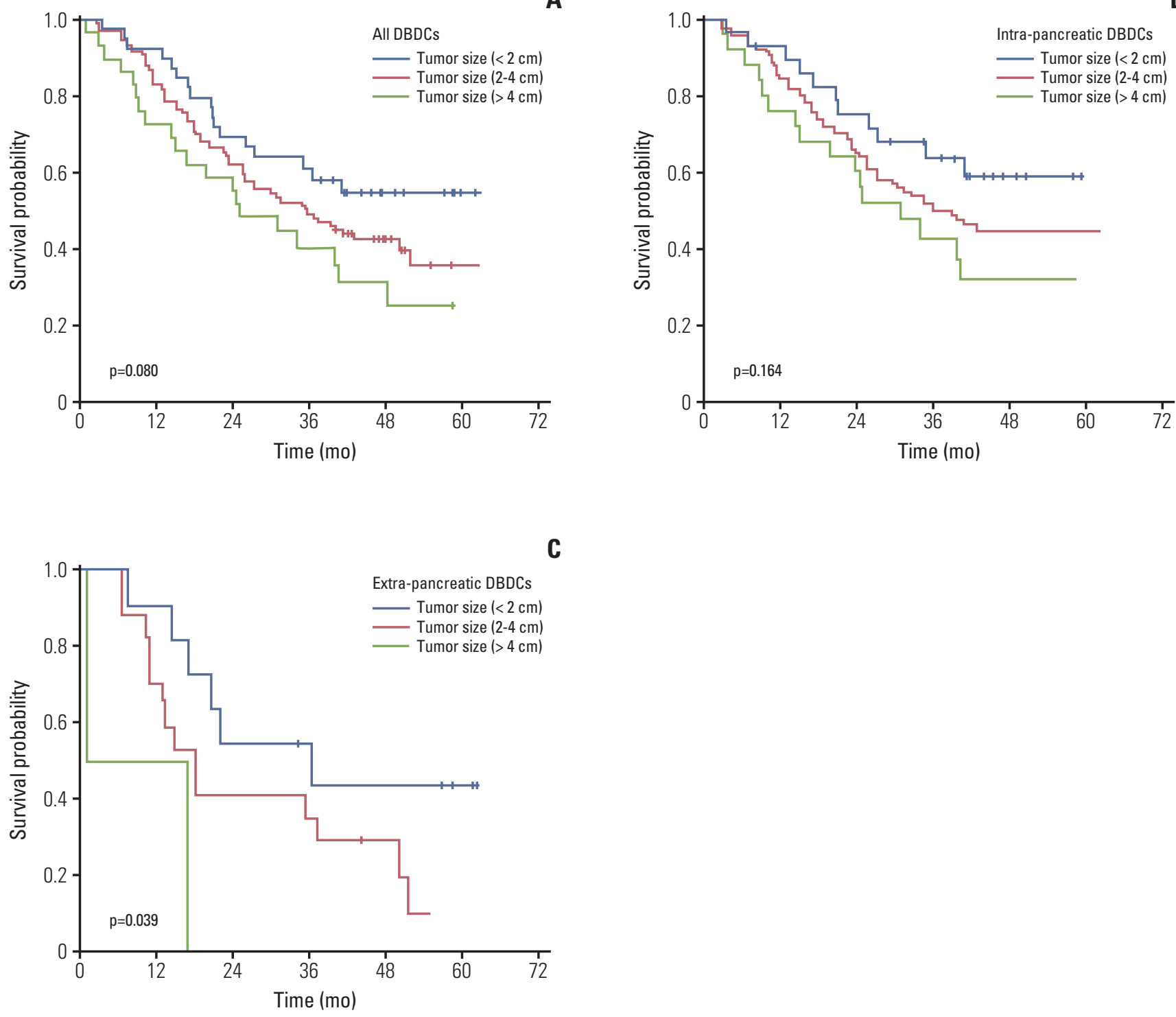

Fig. 4. Overall survival stratified by size-based criteria of distal bile duct carcinomas (DBDCs). All DBDCs (A), including intra-pancreatic, extra-pancreatic, and both intra- and extra-pancreatic types. Intra-pancreatic (B) and extra-pancreatic (C) DBDCs.

$32.5 \%)$, and IIIA $(17,8.5 \%)$. Neither stages IIIB nor IV were seen among our cases. The stage grouping of the new eighth edition was a strong predictor of long-term outcome $(\mathrm{p}<$ 0.001) (Fig. 3A). By pairwise comparisons, the 5-YSR of stage IIA patients was significantly better than that of stage IIB patients $(\mathrm{p}<0.001)$. However, other pairs of stage groupings showed no significant differences in patient survival (stages I and IIA, $\mathrm{p}=0.148$; IIB and IIIA, $\mathrm{p}=0.691$ ), corresponding to the 5 -YSRs of $59.0 \%, 52.4 \%, 12.9 \%$, and $14.7 \%$ for patients with stage I, IIA, IIB, and IIIA tumors, respectively. After simplifying the stage grouping, patients with stages II and III tumors had a median survival of 31.6 and 17.0 months, respectively. The median survival of patients with stage I tumors had not been reached, because more than $50 \%$ of the patient were still alive. Consequently, patients with higher stage tumors tended to have significantly shorter survival $(p<0.001)$ (Fig. 3B). When pairwise comparisons were performed, all pairs of stages were significantly correlated to patient survival (stages I and II, $\mathrm{p}=0.002$; II and III, $\mathrm{p}=0.015$ ). This corresponded to a 5-YSR of $35.4 \%$ and $14.7 \%$ for patients 
Table 4. Univariate and multivariate analysis of distal bile duct carcinoma patients

\begin{tabular}{|c|c|c|c|c|c|c|c|}
\hline \multirow{2}{*}{ Variable } & \multicolumn{4}{|c|}{ Univariate analysis } & \multicolumn{3}{|c|}{ Multivariate analysis } \\
\hline & 5-YSR (\%) & HR & $95 \% \mathrm{CI}$ & p-value & HR & $95 \% \mathrm{CI}$ & p-value \\
\hline Location & & & & 0.098 & & & \\
\hline Extra-pancreatic & 23.2 & - & - & - & & & \\
\hline Intra-pancreatic & 44.7 & 0.6 & $0.4-1.0$ & $0.041^{\text {a) }}$ & & & \\
\hline Both intra- and extra-pancreatic & 0 & 1.4 & $0.3-5.9$ & 0.662 & & & \\
\hline Growth pattern & & & & $0.001^{\text {a) }}$ & & & 0.070 \\
\hline Papillary & 55.6 & - & - & - & - & - & - \\
\hline Nodular & 64.8 & 1.2 & $0.4-3.6$ & 0.808 & 1.5 & $0.3-7.5$ & 0.626 \\
\hline Diffusely infiltrative & 30.6 & 2.9 & $1.1-7.8$ & $0.041^{\text {a) }}$ & 2.8 & $0.7-12.4$ & 0.168 \\
\hline Size $(\mathrm{cm})$ & & & & 0.082 & & & \\
\hline$<2$ & 54.6 & - & - & - & & & \\
\hline $2-4$ & 35.4 & 1.5 & $0.9-2.5$ & 0.146 & & & \\
\hline$>4$ & 25.0 & 2.1 & $1.1-4.0$ & $0.026^{\mathrm{a})}$ & & & \\
\hline Involvement of bile duct margin by cancer & 18.2 & 2.1 & $1.4-3.1$ & $0.001^{\text {a) }}$ & 1.3 & $0.7-2.4$ & 0.340 \\
\hline Lymphovascular invasion & 33.9 & 1.5 & $1.1-2.2$ & $0.022^{\mathrm{a})}$ & 1.5 & $1.0-2.3$ & 0.085 \\
\hline Pancreatic invasion & 33.9 & 3.4 & $2.0-5.9$ & $<0.001^{\text {a) }}$ & 2.3 & $1.3-4.0$ & $0.006^{\mathrm{a})}$ \\
\hline Duodenal invasion & 32.2 & 1.9 & $1.3-2.9$ & $0.003^{\mathrm{a})}$ & 0.9 & $0.6-1.6$ & 0.804 \\
\hline T category (eighth AJCC) & & & & $<0.001^{\text {a) }}$ & & & $0.014^{\mathrm{a})}$ \\
\hline $\mathrm{T} 1(<5 \mathrm{~mm})$ & 59.3 & - & - & - & - & - & - \\
\hline $\mathrm{T} 2(5-12 \mathrm{~mm})$ & 42.4 & 2.3 & $1.2-4.3$ & $0.013^{\text {a) }}$ & 1.6 & $0.7-4.0$ & 0.281 \\
\hline $\mathrm{T} 3(>12 \mathrm{~mm})$ & 12.2 & 5.2 & $2.6-10.1$ & $<0.001^{\text {a) }}$ & 3.0 & $1.2-7.7$ & $0.023^{a)}$ \\
\hline N category (eighth AJCC) & & & & $<0.001^{\text {a) }}$ & & & $0.029^{\mathrm{a})}$ \\
\hline N0 & 47.3 & - & - & - & - & - & - \\
\hline N1 (1-3) & 17.0 & 2.5 & $1.7-3.8$ & $<0.001^{\text {a) }}$ & 1.7 & $1.1-2.8$ & $0.030^{\mathrm{a})}$ \\
\hline $\mathrm{N} 2(\geq 4)$ & 14.7 & 3.1 & $1.7-5.6$ & $<0.001^{\text {a) }}$ & 2.2 & $1.1-4.3$ & $0.024^{\text {a) }}$ \\
\hline
\end{tabular}

5-YSR, 5-year survival rate; HR, relative hazards ratio; CI, confidence interval; AJCC, American Joint Committee on Cancer.

a)Statistically significant $(\mathrm{p}<0.05)$.

with stage II and III tumors, respectively, and $59.0 \%$ for those with stage I tumors.

On the contrary, survival of the seventh AJCC stage grouping is presented in Fig. $3 \mathrm{C}$ and D. As noted in Fig. 3C, the seventh AJCC stage grouping also had a good ability to discriminate survival outcome in overall comparison. ( $p<$ $0.001)$. In brief, the 5-YSR of patients with stage IA tumors (91.7\%) was significantly better than that of patients with stage IB $(47.8 \%, \mathrm{p}=0.032)$, and patients with stage IIA tumors $(41.0 \%)$ had significantly better 5-YSR than those with stage IIB $(17.4 \%, \mathrm{p}<0.001)$. However, no significant difference in patient survival was observed between patients with stages IB and IIA ( $\mathrm{p}=0.487)$. After simplifying the stage grouping, only stages I and II were identified. Finally, patients with stage I tumors had a tendency for longer survival than those with stage II tumors ( $\mathrm{p}=0.002$ ) (Fig. 3D), corresponding to a $5-Y S R$ of $59.9 \%$ and $31.1 \%$ for patients with stage I and II tumors, respectively.

\section{Patient survival based on tumor size}

Among patients with DBDCs ( $\mathrm{n}=200)$, about two-thirds of the tumors (132 cases, 66.0\%) were between 2 and $4 \mathrm{~cm}$ in size. Thirty-nine cases $(19.5 \%)$ had tumors $<2 \mathrm{~cm}$ in size and $29(14.5 \%)$ were $>4 \mathrm{~cm}$. The patients with a tumor size $<2$ $\mathrm{cm}$ had better 5-YSRs $(54.6 \%)$ than those with tumors between 2 and $4 \mathrm{~cm}$ (35.4\%), which displayed no significant difference in survival outcomes according to size-criteria ( $\mathrm{p}=0.080)$ (Fig. 4A).

Among intra-pancreatic type tumors $(\mathrm{n}=168)$, similar to the above, $115(68.4 \%)$ were between 2 and $4 \mathrm{~cm}$ in size. Twentyeight $(16.7 \%)$ cases had tumors $<2 \mathrm{~cm}$ in size and 25 (14.9\%) were $>4 \mathrm{~cm}$. Although we analyzed survival in patients with intra-pancreatic type DBDCs only, we could not identify a statistical significance in terms of size-based classification ( $\mathrm{p}=0.164)$ (Fig. 4B).

Conversely, among patients with extra-pancreatic type tumors $(\mathrm{n}=30)$, larger tumor size $(>4 \mathrm{~cm})$ was related to 
worse patient survival ( $\mathrm{p}=0.039)$ (Fig. $4 \mathrm{C})$. There were 11 $(36.7 \%)$ tumors $<2 \mathrm{~cm}$ in size, $17(56.7 \%)$ tumors between 2 and $4 \mathrm{~cm}$, and $2(6.6 \%)$ tumors that were $>4 \mathrm{~cm}$. Both patients with tumor size $>4 \mathrm{~cm}$ died before 1.4 years after surgery. The 5-YSRs of patients with tumor size $<2 \mathrm{~cm}$ and 2 to $4 \mathrm{~cm}$ were $43.6 \%$ and $9.8 \%$, respectively. By pairwise comparison, a significant difference was seen between patients with tumors between 2 and $4 \mathrm{~cm}$ in size and those with $>4 \mathrm{~cm}(\mathrm{p}=0.011)$; however, there was no significant difference in the survival of patients with tumors $<2 \mathrm{~cm}$ in size and those between 2 and $4 \mathrm{~cm}(\mathrm{p}=0.126)$.

\section{Univariate and multivariate analyses}

By univariate analysis, there were no significant differences in survival based on the following: age, sex, postoperative radiation therapy and/or chemotherapy, specified location and size of the tumor, histologic subtype, differentiation, perineural invasion, and gallbladder involvement. However, the following clinicopathologic factors were associated with worse survival of DBDC patients (Table 4): diffusely infiltrative growth pattern $(\mathrm{p}=0.001)$, involvement of bile duct resection margin ( $\mathrm{p}=0.001)$, the presence of lymphovascular $(\mathrm{p}=0.022)$, pancreatic $(\mathrm{p}<0.001)$, and duodenal invasions ( $\mathrm{p}=0.003)$, and $\mathrm{T}$ and $\mathrm{N}$ categories $(\mathrm{p}<0.001$, each). By multivariate analysis, lower $\mathrm{T}(\mathrm{p}=0.014)$ and $\mathrm{N}(\mathrm{p}=0.029)$ categories and the absence of pancreatic invasion $(\mathrm{p}=0.006)$ were good independent prognostic predictors of overall survival in DBDC patients.

\section{Discussion}

Our present study validates the new eighth edition of the AJCC staging system in patients with DBDC and reveals that it was superior to the seventh edition in terms of predicting patient prognosis.

For any given malignancy, TNM staging is one of the most powerful prognostic indicators of disease-specific survival. In general, the pathologic $\mathrm{T}$ category is defined by anatomic and histologic findings. The hollow viscus organs in the gastrointestinal tract have a well-defined anatomic layering, so it is easier to clarify $\mathrm{T}$ classification by anatomic layering, for example, the lamina propria, muscularis mucosa, submucosa, muscularis propria, subserosa, and serosa. However, for the biliary tree, it is difficult to define the bile duct boundary with obvious anatomic descriptions owing to a thin wall, sparse and incomplete smooth muscle, and abundant vascular and neural networks of periductal adipose tissue [8]. Moreover, particularly in cancer status, the bile duct bound- ary is commonly obscured by desmoplastic reactions and inflammation, which makes the distinction between $\mathrm{T} 2$ and T3 of the seventh edition AJCC more difficult in DBDC [7]. In addition to a problematic and unclear anatomic definition, the $\mathrm{T}$ category of the seventh edition AJCC staging system failed to reveal a significant relationship with patient outcome $[7,13]$. Conversely, the progressive new T category of the eighth AJCC for DBDC can be applied objectively and has shown reliable results in the prediction of patient outcome $[9,12,13]$. The predictive role of the $\mathrm{T}$ category of the eighth edition AJCC staging system for DBDC in terms of patient prognosis has been described in a few studies conducted in Western [9] and Eastern [13] countries. Previously, our group proposed a new $\mathrm{T}$ category measuring the depth of invasion in DBDCs and demonstrated its strong correlation with patient survival [9]. A validation study by Moon et al. [13] also reported that the T category of the eighth AJCC for DBDC was significantly associated with patient survival $(p<0.001)$ [13]. However, they did not observe a difference in survival among patients with $\mathrm{T} 2$ and $\mathrm{T} 3$ tumors $(\mathrm{p}=0.16)$, albeit differences were observed between $\mathrm{T} 1$ and $\mathrm{T} 2$ tumors $(\mathrm{p}=0.004)$. On the contrary, we revealed that the T category of the eighth AJCC staging system for DBDC discriminated patient survival in both pairwise (T1 and T2, $\mathrm{p}=0.011$; $\mathrm{T} 2$ and T3, $\mathrm{p}<0.001)$ and overall $(\mathrm{p}<0.001)$ comparisons. This discrepancy may be related to the small number of T3 cases $(13 / 117,11.7 \%)$ analyzed in the previous study [13].

We also evaluated survival difference by Gonzalez's sizebased criteria for staging in our DBDC cases, but could not find any survival differences. Based on our observations, the sized-based proposal by Gonzalez et al. [1] did not segregate patient survival of DBDCs. This result suggested that a T category based on invasion depth has more important survival implications than a T category based on cancer size in DBDCs, similar to T categories of other hollow viscus organs, such as stomach and colorectal cancers.

Several groups demonstrated a minimum of 10 lymph nodes should be examined for the precise evaluation of nodal status of DBDCs $[13,21]$. Schwartz and Smith analyzed the Surveillance, Epidemiology, and End Results (SEER) data and demonstrated that patient survival was strongly influenced by the total examined lymph node count [21]. Moon et al. [13] evaluated various cut-off values according to the number of total lymph nodes examined using 111 cases and revealed the cut-off value was 10 ( 1 to 9 vs. $\geq 10$ of total number of nodes assessed) for differentiating patient survival time [13]. On the contrary, our group previously concluded that increasing retrieval of nodes does not affect patient survival in EBD carcinomas, but this study contained both perihilar cholangiocarcinomas and DBDCs and did not discriminate patient survival [22]. Therefore, we investigated the difference in patient survival time between groups with 1 to 


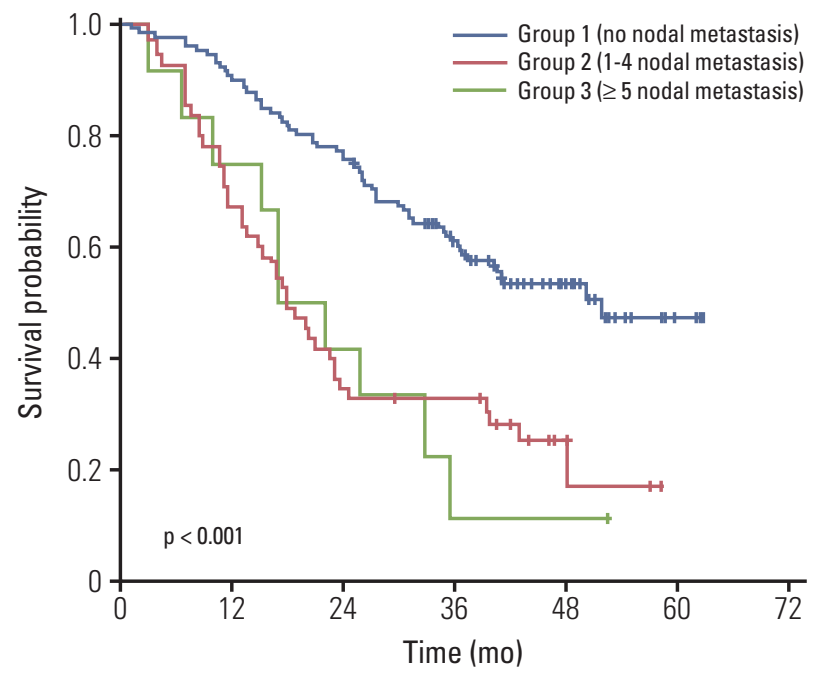

Fig. 5. Overall survival stratified by number of metastatic lymph nodes.

9 and 10 or more lymph nodes examined, using our present cases; however, no statistically significant differences were observed between the two groups ( $\mathrm{p}=0.670$, data not shown).

Including our present study, several previous studies demonstrated the prognostic significance of the 3 tiered $\mathrm{N}$ category $[13,22,23,25]$. In present study, we observed significant survival differences among DBDC patients based on $\mathrm{N}$ category of the eighth AJCC staging system in overall comparison and in pairwise comparison between N0 and N1 patients, similar to the previous studies $[13,22,23,25]$. However, there are discrepant results of patients' survival between N1 and N2 groups. We did not find significant survival difference between N1 and N2 patients, which was concordant with that of Kang et al.'s study [25]. However, different with the present study, previous results of Moon et al. [13] and Kiriyama et al. [23] demonstrated significant differences in survival between patients with N1 and N2 tumors $[13,23]$. Due to this discrepancy in patients' survival analysis between N1 and N2 groups, further multi-center studies with large number of cases are required for validating $\mathrm{N}$ category of the eighth AJCC staging system.

Our group previously proposed a different cutoff for nodal classification, comprising group 1 (no nodal metastasis), group 2 (1-4 nodal metastases), and group 3 ( $\geq 5$ nodal metastases) [22]. However, our previous study included both perihilar cholangiocarcinomas and DBDCs [22]. We divided our present cases into group 1 (133 cases, 66.5\%), group 2 (55, $27.5 \%)$, and group $3(12,6.0 \%)$ according to our previously proposed criteria for the $\mathrm{N}$ category, and demonstrated a statistically significant difference between three groups, similar to results of the $\mathrm{N}$ category of the eighth edition $(\mathrm{p}<0.001)$ (Fig. 5). The median survival times of the patients in groups 2 and 3 (18.0 and 17.0 months, respectively) were shorter than that of patients in group 1 (51.8 months; $\mathrm{p}<0.001$, each). Meanwhile, there was no significant difference in survival time between the patients in groups 2 and 3 ( $p=0.765)$, similar to the results of the $\mathrm{N}$ category of the eighth edition. Consequently, further studies are needed to enhance the predictive role of the N category of DBDCs in terms of patient prognosis.

A few previous studies validated $\mathrm{T}$ category of the eighth AJCC staging scheme of DBDCs [13,25]. Moon et al. [13] demonstrated the superiority of the eighth edition to the seventh edition for predicting patient prognosis, similar to our study. Kang et al. [25] also reported significant survival differences of both pair-wise (T1 vs. T2, T2 vs. T3) and overall comparisons of the eighth edition of the AJCC staging scheme, while no survival difference was observed between $\mathrm{T} 1$ and $\mathrm{T} 2$ comparison of the seventh edition scheme. In concordance with the previous reports, the results of the present study strongly support that the T category of the eighth edition scheme can discriminate DBDC patients' survival better than the previous scheme.

On applying the depth of invasion in DBDCs, there are important things which pathologists and clinicians should be considered. For the pathologists, invasion to adjacent organs, such as direct spread into the pancreas, duodenum, gallbladder, colon, stomach, or omentum, are recommended to be reported in addition to T category, which was descried in the eighth edition AJCC cancer staging manual [14]. For the clinicians, currently preoperative radiologic evaluation for T category of DBDCs is not available due to lack of pathologic-radiologic correlation of depth of invasion of DBDCs. Therefore, further studies of pathologic-radiologic correlation of depth of invasion of DBDCs are required.

Our study has a few limitations. First, the present study was a single institutional study and included 200 cases. Although 200 cases were not small case number for statistical analysis, further multi-institutional or multi-national studies with larger number of cases and longer follow-up period are required for more solid conclusion. Second, no T4 cases were seen in the present study, because all included cases were only surgically resected cases. Therefore, the further study including both surgically resected and unresectable cases is required for survival comparisons between T3 and T4 groups.

In summary, the current eighth edition of the AJCC cancer staging system for DBDCs changed the $\mathrm{T}$ and $\mathrm{N}$ categories, which enhanced its ability to discriminate patient survival beyond that of the previous scheme of the seventh edition. Further changes are needed for better survival estimation in patients with DBDCs. 


\section{Conflicts of Interest}

Conflict of interest relevant to this article was not reported.

\section{Acknowledgments}

This research was supported by the Basic Science Research Program through the National Research Foundation of Korea (NRF) funded by the Ministry of Science, ICT and Future Planning (NRF2012R1A1A2003360).

\section{References}

1. Gonzalez RS, Bagci P, Basturk O, Reid MD, Balci S, Knight JH, et al. Intrapancreatic distal common bile duct carcinoma: analysis, staging considerations, and comparison with pancreatic ductal and ampullary adenocarcinomas. Mod Pathol. 2016;29:1358-69.

2. Shin HR, Oh JK, Masuyer E, Curado MP, Bouvard V, Fang Y, et al. Comparison of incidence of intrahepatic and extrahepatic cholangiocarcinoma: focus on East and South-Eastern Asia. Asian Pac J Cancer Prev. 2010;11:1159-66.

3. Albores-Saavedra J, Adsay NV, Crawford JM, Klimstra DS, Kloppel G, Sripa B, et al. Tumours of the gallbladder and extrahepatic bile ducts. In: Bosman FT, Carneiro F, Hruban $\mathrm{RH}$, Theise ND, editors. WHO classification of tumours of digestive system. 4th ed. Lyon: IARC Press; 2010. p. 266-73.

4. Siegel RL, Miller KD, Jemal A. Cancer statistics, 2015. CA Cancer J Clin. 2015;65:5-29.

5. Beahrs OH, Henson DE, Hutter RV, Kennedy BJ. American Joint Committee in Cancer. Manual for staging of cancer. 4th ed. Philadenphia, PA: J.B. Lippincott Company; 1992.

6. Fleming ID, Cooper JS, Henson DE, Hutter RV, Kennedy BJ, Murphy GP, et al. AJCC cancer staging manual. 5th ed. Philadelphia, PA: Lippincott-Raven; 1997.

7. Hong SM, Kim MJ, Pi DY, Jo D, Cho HJ, Yu E, et al. Analysis of extrahepatic bile duct carcinomas according to the New American Joint Committee on Cancer staging system focused on tumor classification problems in 222 patients. Cancer. 2005; 104:802-10.

8. Hong SM, Presley AE, Stelow EB, Frierson HF Jr, Moskaluk CA. Reconsideration of the histologic definitions used in the pathologic staging of extrahepatic bile duct carcinoma. Am J Surg Pathol. 2006;30:744-9.

9. Hong SM, Pawlik TM, Cho H, Aggarwal B, Goggins M, Hruban $\mathrm{RH}$, et al. Depth of tumor invasion better predicts prognosis than the current American Joint Committee on Cancer T classification for distal bile duct carcinoma. Surgery. 2009;146:250-7.

10. Edge SB, Byrd DR, Campton CC, Fritz AG, Greene FL, Trotti A. AJCC cancer staging manual. 7th ed. New York: SpringerVerlag; 2010.

11. Greene FL, Page DL, Fleming ID, Fritz AG, Balch CM, Haller DG, et al. AJCC cancer staging manual. 6th ed. New York: Springer-Verlag; 2002.

12. Hong SM, Cho H, Moskaluk CA, Yu E. Measurement of the invasion depth of extrahepatic bile duct carcinoma: an alternative method overcoming the current $\mathrm{T}$ classification problems of the AJCC staging system. Am J Surg Pathol. 2007;31: 199-206.

13. Moon A, Choi DW, Choi SH, Heo JS, Jang KT. Validation of T stage according to depth of invasion and $\mathrm{N}$ stage subclassification based on number of metastatic lymph nodes for distal extrahepatic bile duct (EBD) carcinoma. Medicine (Baltimore). 2015;94:e2064.

14. Edge SB, Greene FL, Schilsky RL, Gaspar LE, Washington MK, Sullivan DC, et al. AJCC cancer staging manual. 8th ed. Basel: Springer Nature; 2017.

15. Yoshida T, Aramaki M, Bandoh T, Kawano K, Sasaki A, Matsumoto T, et al. Para-aortic lymph node metastasis in carcinoma of the distal bile duct. Hepatogastroenterology. 1998;45: 2388-91.

16. Yoshida T, Aramaki M, Matsumoto T, Morii Y, Sasaki A, Kitano S. The pattern of lymphatic spread in carcinoma of the distal bile duct. Int Surg. 1998;83:124-7.

17. Yoshida T, Shibata K, Yokoyama H, Morii Y, Matsumoto T, Sasaki A, et al. Patterns of lymph node metastasis in carcinoma of the distal bile duct. Hepatogastroenterology. 1999;46: 1595-8.

18. Yoshida T, Matsumoto T, Sasaki A, Morii Y, Aramaki M, Kitano S. Prognostic factors after pancreatoduodenectomy with extended lymphadenectomy for distal bile duct cancer. Arch Surg. 2002;137:69-73.

19. Yoshida T, Matsumoto T, Sasaki A, Morii Y, Shibata K, Ishio $\mathrm{T}$, et al. Lymphatic spread differs according to tumor location in extrahepatic bile duct cancer. Hepatogastroenterology. 2003;50:17-20.

20. Yoshida T, Matsumoto T, Sasaki A, Shibata K, Aramaki M, Kitano S. Outcome of paraaortic node-positive pancreatic head and bile duct adenocarcinoma. Am J Surg. 2004;187:736-40.

21. Schwarz RE, Smith DD. Lymph node dissection impact on staging and survival of extrahepatic cholangiocarcinomas, based on U.S. population data. J Gastrointest Surg. 2007;11: 158-65.

22. Hong SM, Cho H, Lee OJ, Ro JY. The number of metastatic lymph nodes in extrahepatic bile duct carcinoma as a prognostic factor. Am J Surg Pathol. 2005;29:1177-83.

23. Kiriyama M, Ebata T, Aoba T, Kaneoka Y, Arai T, Shimizu Y, et al. Prognostic impact of lymph node metastasis in distal 
cholangiocarcinoma. Br J Surg. 2015;102:399-406.

24. Hamilton SR, Bosman FT, Boffetta P, Ilyas M, Morreau H, Nakamura SI, et al. Carcinoma of the colon and rectum. In: Bosman FT, Carneiro F, Hruban RH, Theise ND, editors. WHO classification of tumours of the digestive system. 4th ed. Lyon: IARC Press; 2010. p. 134-46.
25. Kang JS, Lee S, Son D, Han Y, Lee KB, Kim JR, et al. Prognostic predictability of the new American Joint Committee on Cancer 8th staging system for distal bile duct cancer: limited usefulness compared with the 7th staging system. J Hepatobiliary Pancreat Sci. 2018;25:124-30. 